\title{
Spatial-temporal variability of thermohaline intrusions in the northwestern tropical Pacific Ocean
}

\author{
LI YuanLong, WANG Fan ${ }^{*} \&$ TANG XiaoHui \\ Key Laboratory of Ocean Circulation and Waves, Institute of Oceanology, Chinese Academy of Sciences, Qingdao 266071, China
}

Received February 9, 2012; accepted June 7, 2012; published online November 28, 2012

\begin{abstract}
Using repeated hydrographic measurements at $137^{\circ} \mathrm{E}$, spatial-temporal variability of thermohaline intrusions in the northwestern tropical Pacific are investigated. Intrusions can be found in the main thermocline throughout the section, with their strength decreasing rapidly poleward. The strongest intrusions exist at the North Equatorial Countercurrent (NECC) where North/South Pacific thermocline water converges. These intrusions also exhibit temporal variations in strength which are closely associated with the meridional displacement of the NECC. Intrusion strength peaks in boreal winter when the NECC reaches its northernmost position of the year. At interannual time scale, intrusions tend to be weak (strong) during El Niño (La Niña) episodes. Variations in intrusion strength also lead to prominent fluctuation of lateral diffusivity $K_{\mathrm{L}}$ and cross-front temperature flux $F_{\Theta}$. $F_{\Theta}$ exhibits significant year-to-year changes which are well correlated with ENSO index, suggesting a possible role of intrusions in the low-latitude Pacific climate variability.
\end{abstract}

thermohaline intrusions, northwestern tropical Pacific, water mass, ENSO, mixing

Citation: $\quad$ Li Y L, Wang F, Tang X H. Spatial-temporal variability of thermohaline intrusions in the northwestern tropical Pacific Ocean. Chin Sci Bull, 2013, 58: 1038-1043, doi: 10.1007/s11434-012-5359-9

Thermohaline intrusions are a type of oceanic thermohaline finestructure produced by lateral water mass interleaving and featured by alternating warm-salty and cold-fresh water layers with a vertical scales ranging from 1 to $100 \mathrm{~m}$ [1]. Strong intrusions are usually observed at oceanic fronts and water mass boundaries where lateral temperature $(T)$ / salinity $(S)$ gradients are large. Thermohaline intrusions are focused by oceanographers primarily because of their direct connection to lateral mixing [2]. The northwestern Pacific Ocean is characterized by complicated upper-ocean circulation. Zonal currents bring water masses from various formation regions. Strongly contrasting $T-S$ properties of the water masses form sharp fronts where thermohaline intrusions could develop. Dramatic property change of water masses due to mixing in this region has been described by many studies [3-6], in which intrusions may play an important role. Hence, for a better understanding of oceanic physical processes in this region, a particular investigation

*Corresponding author (email: fwang@qdio.ac.cn) of thermohaline intrusions is necessary.

The existence and richness of thermohaline intrusions in this region have been reported by several previous studies. Among them, those observed near the equator are especially striking [7]. They are of a vertical scale of $O(10 \mathrm{~m})$ and featured by remarkable lateral coherence $[7,8]$. The effective lateral diffusion due to these intrusions can be of an order of $10^{3} \mathrm{~m}^{2} \mathrm{~s}^{-1}$ which has been large enough to affect large-scale dynamics [9]. Richards and Edwards [9] pointed out that a larger lateral diffusion near the equator can greatly improve the simulation of upper-ocean structures like the Equatorial Undercurrent (EUC) and the East Pacific cold tongue. However, these findings are mainly confined at the equator and in the near-surface layer. The overall threedimensional spatial distribution of intrusions in the northwestern Pacific is unknown. Moreover, temporal variability of these intrusions, such as the seasonal cycle and interannual changes, has never been addressed in the oceanographic literature.

Comparing with other oceanographic themes, the re- 
searches of thermohaline intrusions suffer worse from the shortage and paucity of in-situ observations, because only high-resolution data can resolve the subtle spatial structure of intrusions. The only available long-term repeated hydrographic dataset in the northwestern Pacific is by the once-per-season cruises of the Japan Meteorological Agency (JMA) along $137^{\circ} \mathrm{E}$ meridian. This section starts from $34^{\circ} \mathrm{N}$ south of Japan and ends at $3^{\circ} \mathrm{N}$ near the New Guinea coast, cutting across the entire mid- and low-latitude northwestern Pacific Ocean (Figure 1). The data in each season from 1997 to 2010 are available at the website http://www. jma.go.jp/jma/indexe.html. Conductivity-temperature-depth (CTD) stations are mostly spaced in $1^{\circ}$-latitude bins with a vertical resolution of $1 \mathrm{dbar}$ and temperature (salinity) uncertainty smaller than $\pm 0.005^{\circ} \mathrm{C}( \pm 0.0005 \mathrm{psu})$. In this study we use these profiles to explore the spatial distribution and temporal variations of thermohaline intrusions at this section.

\section{Methodology of intrusion detection}

Isopycnal salinity anomaly, which is also referred to as spice anomaly, is commonly used in recent observational studies of intrusion $[7,8,10]$. This method is proven to be

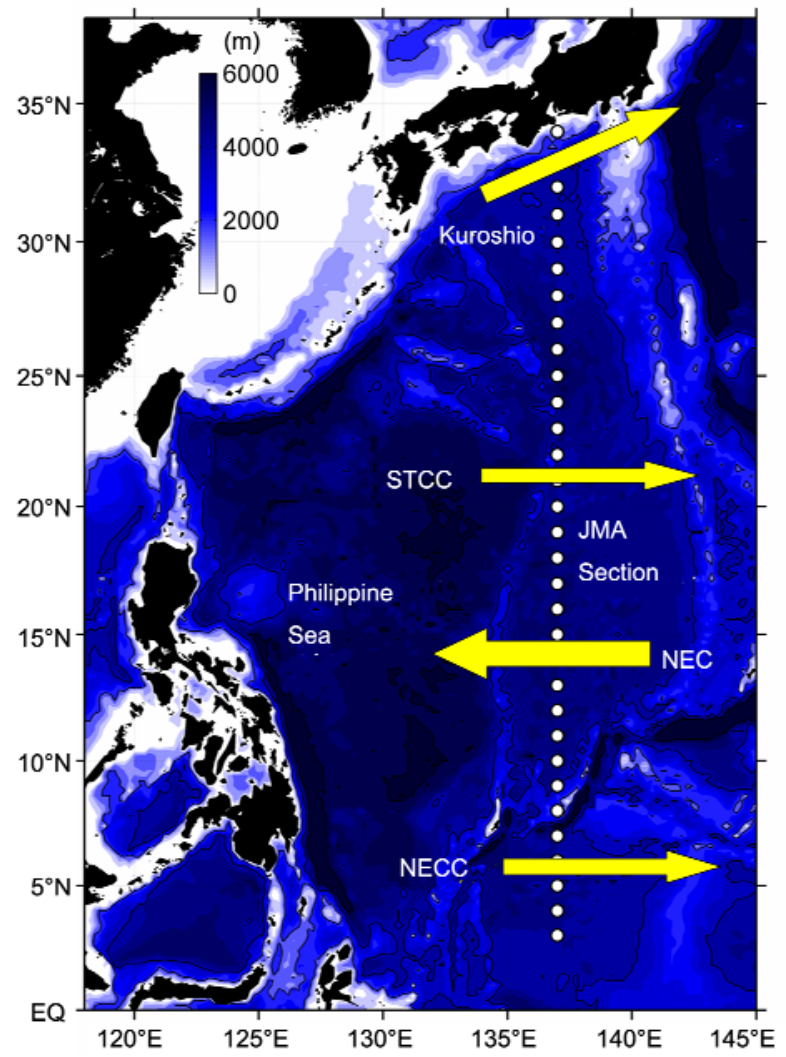

Figure 1 Topography of the northwestern Pacific Ocean (color shading) and the geographic location of the JMA $137^{\circ} \mathrm{E}$ section at which CTD stations (white dots) are spaced in $1^{\circ}$-latitude bins. Yellow arrows denote the main currents flowing across the section. STCC, The Subtropical Countercurrent; NEC, the North Equatorial Current; NECTC, the North Equatorial Countercurrent. effective in detecting intrusion signals and quantifying intrusion strength. The background salinity $S_{B}$ can be obtained by vertically smoothing the original salinity $S$ profile. However, the results are, to some extent, sensitive to the choice of parameters of the filter, like the cutoff length. For example, the sharp subsurface salinity maximum in the upper thermocline is easy to be mistaken as a large positive anomaly. Thus a small cutoff is required in the shallow layer. On the other hand, intrusions in a deeper layer are often of larger vertical scales (see Table 1 of Ruddick and Richards [2]), which demands a larger cutoff. In addition, density stratification can be greatly different between low- and mid-latitude profiles. Using one set of parameters, a smoothing under pressure/depth coordinate can not produce reasonable $S_{B}$ for all the profiles of the section. Besides, salinity anomalies can also be produced by thin well-mixed layers produced by turbulence or double diffusion. These effects will, to a large extent, contaminate the signals of intrusions. Hence we choose to conduct the smoothing under density coordinate, which can greatly diminish the above defects.

Salinity records of the CTD profiles are linearly interpolated onto $0.005 \mathrm{~kg} \mathrm{~m}^{-3}$ density bins. Background salinity $S_{B}$ is calculated by smoothing original $S$ using a fourth-order Butterworth filter with a $0.8 \mathrm{~kg} \mathrm{~m}^{-3}$ cutoff length. Then salinity anomaly $S^{\prime}$ is calculated as $S^{\prime}=S(\sigma)-S_{B}(\sigma)$ under density coordinates and transformed back to pressure space. Our smoothing course provides satisfactory results which can capture the signals of intrusions at all latitudes of the section (Figure 2). To quantify intrusion strength in different layers, after omitting the top $50 \mathrm{dbar}$, a $S^{\prime}$ profile is further broken into 100-dbar segments and the root-meansquared (rms) salinity anomaly $S_{\text {rms }}^{\prime}$ is estimated for each segment. In Figure 2, intrusion signals are clearly discernable in all the profiles shown here. In 2002, intrusions in the main thermocline is much stronger during winter cruise at $4^{\circ}$ and $32^{\circ} \mathrm{N}$, suggesting pronounced seasonal changes of intrusion strength at the NECC and the Kuroshio.

\section{Results}

\subsection{Spatial distribution}

The ensemble-mean $S_{\text {rms }}^{\prime}$ field represents the mean intrusion strength level and provides an overall distribution of intrusions in a climatologic sense (Figure 3(a)). Its standard deviation (STD) is an indicator of temporal variability (Figure 3(b)). Meridional salinity gradient $\left|S_{y}\right|$, which are critical for the development of intrusions, is estimated along isopycnal surfaces using the mean salinity field (Figure 3(c)). Mean geostrophic current relative to $2000 \mathrm{dbar}$ is also shown in Figure 3(d).

Spatial patterns of mean rms $S^{\prime}$, STD of $\mathrm{rms} S^{\prime}$, and $\left|S_{y}\right|$ show great resemblances. Strong intrusions, also with larger temporal variations, mainly develop at water mass 

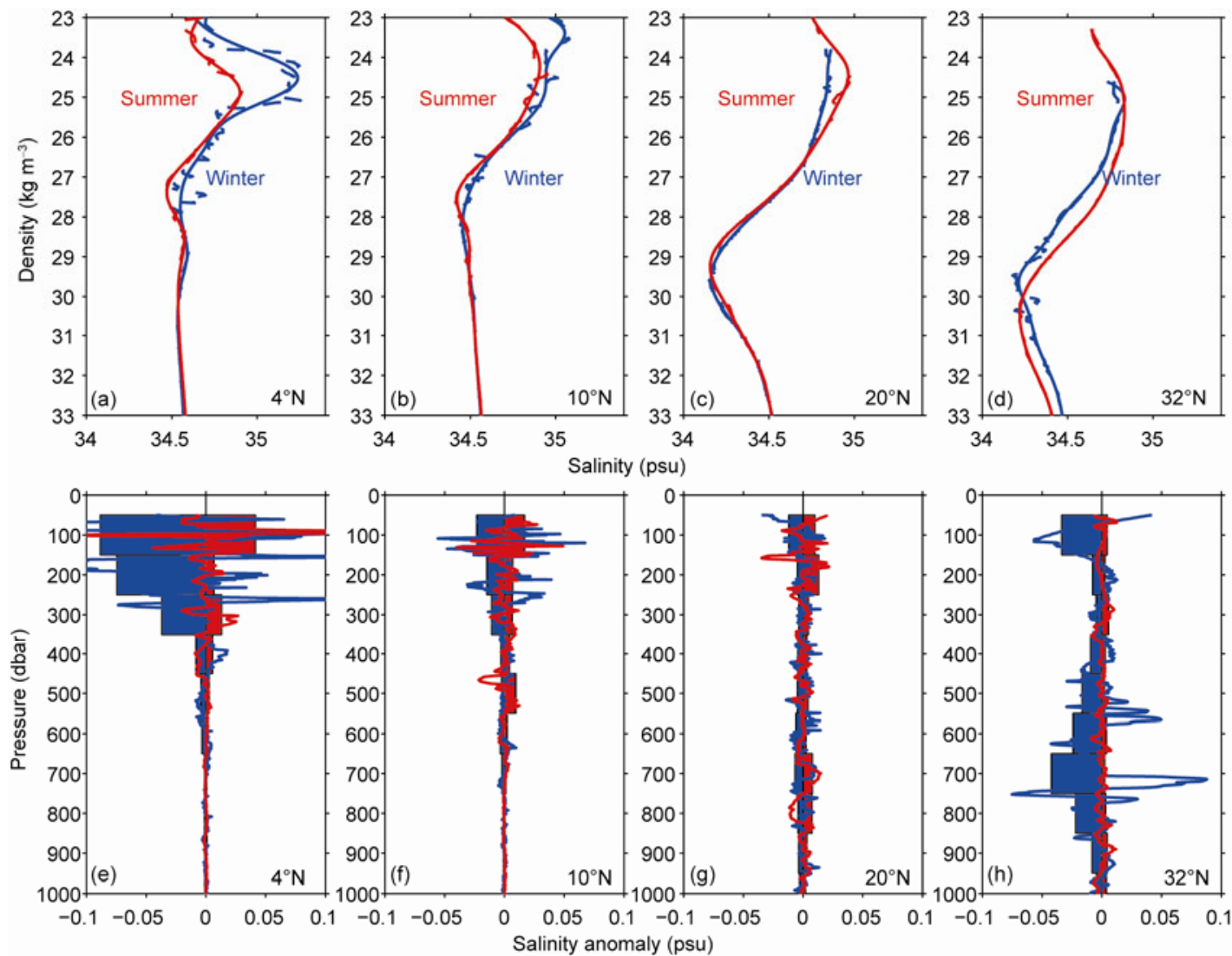

Figure 2 (a)-(d) Original (dashed curve) salinity $S$ (psu) and smoothed (solid curve) salinity $S_{B}$ (psu) profiles with respect to density ( $\left.\mathrm{kg} \mathrm{m}^{-3}\right)$. (e)-(h) salinity anomaly $S^{\prime}$ (curves) and rms salinity anomaly $S_{\text {rms }}^{\prime}$ (bars) calculated in 100-dbar segments. Data of the blue (red) curves and bars are from 2002 winter (summer) cruise at $4^{\circ}, 10^{\circ}, 20^{\circ}$ and $32^{\circ} \mathrm{N}$. Note that the $S_{\text {rms }}^{\prime}$ in 2002 winter cruise has been multiplied by -1 to avoid overlapping.
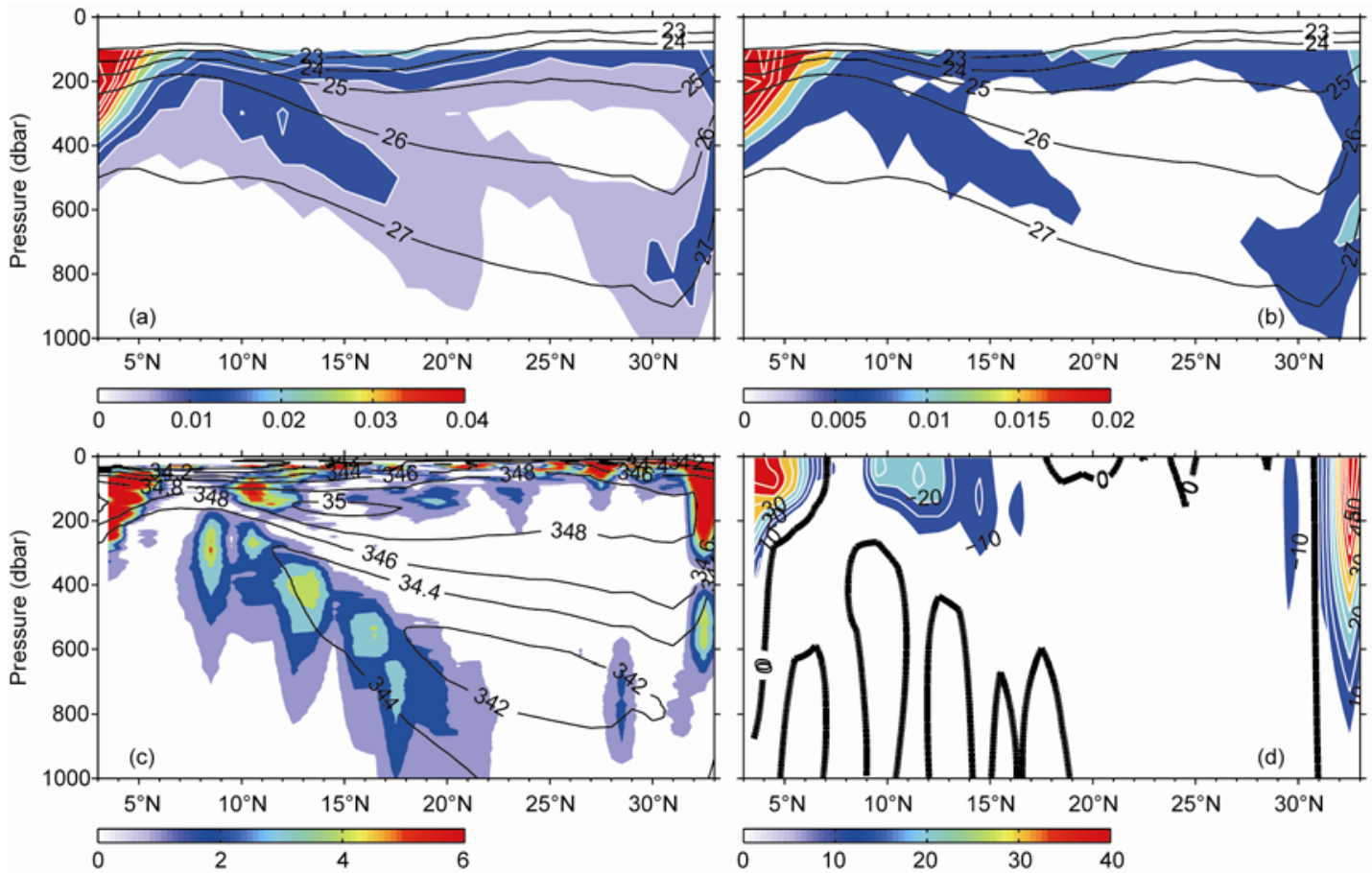

Figure 3 (a) Mean field and (b) standard deviation (STD) of $S_{\text {rms }}^{\prime}$ (psu) with potential density $\left(\mathrm{kg} \mathrm{m}^{-3}\right)$ superimposed as black lines. (c) Absolute meridional salinity gradient $\left|S_{y}\right|\left(10^{-6} \mathrm{psu} \mathrm{m}^{-1}\right)$ with mean salinity (psu) superimposed as black lines. (d) Zonal geostrophic velocity $U$ (black contours in $5 \mathrm{~cm} \mathrm{~s}^{-1}$ interval, unit is $\left.\mathrm{cm} \mathrm{s}^{-1}\right)$ relative to $2000 \mathrm{dbar}$ with color denoting velocity magnitude $\left(\mathrm{cm} \mathrm{s}^{-1}\right)$. 
boundaries. The most intensive intrusions at this section exist near the North Equatorial Countercurrent (NECC) at the southern end of the section, where $\left|S_{y}\right|$ exceeds $6 \times 10^{-6}$ psu $\mathrm{m}^{-1}$ in the upper $300 \mathrm{dbar}$ of the water. The NECC is the boundary between the warm-salty South Pacific Tropical Water (SPTW) and the cold-fresh North Pacific water. The two water masses interleaves into each other, which is the most striking feature of the thermohaline structure in the main thermocline of the western equatorial Pacific [7]. Intrusion strength decreases rapidly with depth and latitude. In the NECC, high $S_{\text {rms }}^{\prime}$ values ( $>0.03 \mathrm{psu}$ ) are mainly confined in the upper $400 \mathrm{dbar}\left(\sim 26.5 \sigma_{\theta}\right)$, which is the lower bound of thermocline water masses. Below that depth, the Antarctic Intermediate Water (AAIW) dominates the entire tropical region, and thus no intrusions can develop. The areas with strong intrusions extend northward to $\sim 7^{\circ} \mathrm{N}$ in the upper 200 dbar, corresponding to the northern limit of the NECC. North of that latitude, intrusions can also be seen in the upper thermocline $\left(\sigma_{\theta}<25.0 \mathrm{~kg} \mathrm{~m}^{-3}\right)$ accompanied with patches of large $\left|S_{y}\right|$ and westward velocities of the NEC. Below the NEC, intrusions with $S_{\text {rms }}^{\prime}>0.015$ psu can be seen in the layer of $\sigma_{\theta}$ $=26.0-26.8 \mathrm{~kg} \mathrm{~m}^{-3}$ between $9^{\circ}-14^{\circ} \mathrm{N}$. These intrusions exist on the boundary between the fresh North Pacific Intermediate Water $(S<34.4 \mathrm{psu})$ in the subtropical gyre and saltier tropical Pacific intermediate water masses.

At the northern end of the section, intrusions can be seen in the Kuroshio (eastward flow exceeding $50 \mathrm{~cm} \mathrm{~s}^{-1}$ south of Japan). It is noticeable that all the background thermohaline and dynamic factors in the Kuroshio, like $\left|S_{y}\right|$, velocity shears, and baroclinicity are similar, or at least, comparable to those in the NECC. But the intrusions in the Kuroshio are much weaker. This pattern supports the idea that interleaving in the western equatorial Pacific is driven by a unique mechanism. Richards and Banks [7] have found that features of interleaving layers in the western equatorial Pacific are consistent with the prediction of both double diffusion and inertial instability theoretical models. Intrusions near the western equatorial Pacific may be driven by both the two processes [11]. Near the equator, Coriolis parameter $f$, representing the planetary vorticity, is much smaller than that at mid-latitudes. Strong shears in the EUC and NECC, indicating a large relative vorticity, make the water much more vulnerable to near-inertial velocity instabilities.

\subsection{Temporal variations}

Figures 2 and 3 have suggested the prominent temporal variability of intrusion strength at this section. Since the intrusions in the tropical Pacific are particularly striking and potentially important in the tropical ocean dynamics [7,9], we then particularly explore their variations at seasonal and interannual time scales. Figure 4(a) shows the time-latitude plot of $S_{\text {rms }}^{\prime}$ calculated between 22.5-25.5 $\sigma_{\theta}$. Large $S_{\text {rms }}^{\prime}$ values ( $>0.04 \mathrm{psu}$ ) only appear in the south. As proceeding northward, $S_{\text {rms }}^{\prime}$ drops abruptly from $>0.04$ psu to $<0.02 \mathrm{psu}$, marking the northern boundary of the high $S_{\text {rms }}^{\prime}$ area. This boundary migrates north and south with time, showing an evident seasonal cycle superimposed by interannual fluctuations. It is noticeable that high $S_{\text {rms }}^{\prime}$ values are basically enveloped by the 34.9-psu isohaline which fluctuates accordingly. A similar fluctuation can be seen in zonal velocity fields (Figure 4(b)). Strong eastward velocities $\left(>30 \mathrm{~cm} \mathrm{~s}^{-1}\right)$, representing the NECC, is also accompanied by $S>34.9$ psu water. As the NECC is the South/North Pacific water

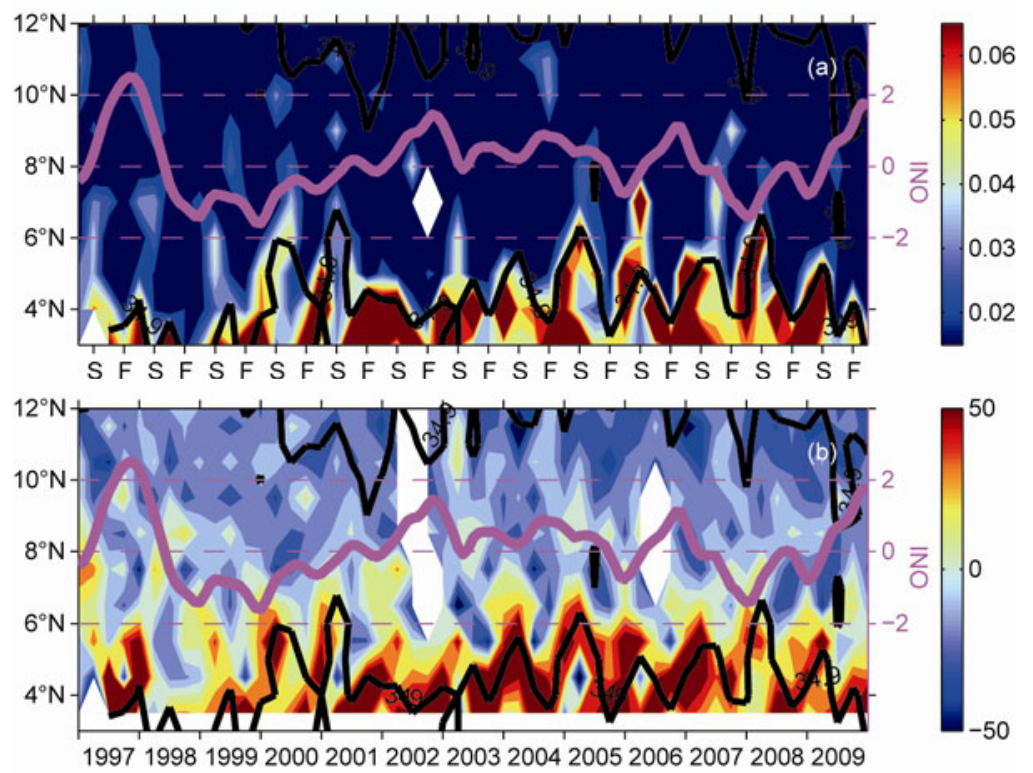

Figure 4 (a) Time-latitude plots of $S_{\text {rms }}^{\prime}$ (psu) and (b) zonal geostrophic velocity $U$ (in $\mathrm{cm} \mathrm{s}^{-1}$; positive values indicates eastward velocities) averaged between 22.5-25.5 $\sigma_{\theta}$ with 34.9-psu isohalines superimposed as black curves. The Oceanic Niño Index (ONI) is also plotted as a pink curve and scaled on the right axis. On the $x$-axis of (a), S denotes spring, while $\mathrm{F}$ denotes fall. 
boundary, its meridional displacement leads to significant oceanic variations between $4^{\circ}-6^{\circ} \mathrm{N}$. In boreal winter (DJF), the NECC shifts northward, and more salty SPTW can be observed between $4^{\circ}-6^{\circ} \mathrm{N}$. The seasonal variation of water mass property has been described by Kashino et al. [12] using mooring observations at $5^{\circ} \mathrm{N}$. Our results reveal that the northward NECC migration also carries strong thermohaline intrusions to the north. It is also noticeable that in some years, strong intrusion reaches northernmost in winter (e.g. in 2001, 2003, 2004, and 2007), but the 34.9-psu isohaline always reaches northernmost in spring. The one-season lag is more evident between the NECC velocity and the 34.9-psu isohaline (Figure 4(b)).

By averaging variables for each season, we get the mean annual cycles which are most evident at $5^{\circ} \mathrm{N}$ (Figure 5(a) -(c)). Salinity begins to rise in winter, peaks in spring, and subsequently decreases from summer to fall. Zonal velocity is greatly enhanced in winter corresponding to the northward shift of the NECC; intrusion strength also shows a significant jump from fall to winter and gradually decreases afterward. This one-season phase lag between salinity and intrusion strength suggests the role of intrusions in water mass property change. Strong intrusions produce continuous northward heat/salt fluxes in winter, which leads to the salinity elevation from winter to spring.

We then examine the variations at ENSO time scale.
Figure 4 shows the Oceanic Niño Index (ONI) from the Climate Prediction Center (CPC) of the National Oceanic and Atmospheric Administration (NOAA). During the period of observation, 2 strong warm events (1997/1998 and 2009/2010), and 2 strong cold events (1999/2000 and $2007 / 2008$ ) can be identified. Between $4^{\circ}-6^{\circ} \mathrm{N}$, intrusion strength is evidently lower during the 1997/1998 and 2009/2010 El Niños, and higher during 1999/2000 and 2007/2008 La Niñas (Figure 4(a)). This fluctuation is also related to the meridional migration of the NECC, which shifts southward in strong ENSO events [13]. Based on on-board observations, Kashino et al. [14] found that the NECC core shifted north during January 2008 Cruise. Also, enhanced interleaving can be seen during that cruise (see Figure 5 of Kashino et al. [14]). Interannual anomaly of $S_{\text {rms }}^{\prime}$ at $5^{\circ} \mathrm{N}$ (Figure 5(d)), which is obtained by subtracting the annual cycle, shows a peak-to-peak difference of $\sim 0.1$ psu and a negative correlation with the ONI of -0.35 (significant at $99 \%$ confidence level).

Variations in intrusion strength lead to fluctuation of meridional heat/salt flux. According to the equilibrium of Joyce [15], a balance holds between the small scale vertical diffusions between alternating interleaving layers and cross-front flux. For salinity, it is expressed as

$$
v_{L} \overline{S_{y}} \simeq K_{V} S_{z z}
$$
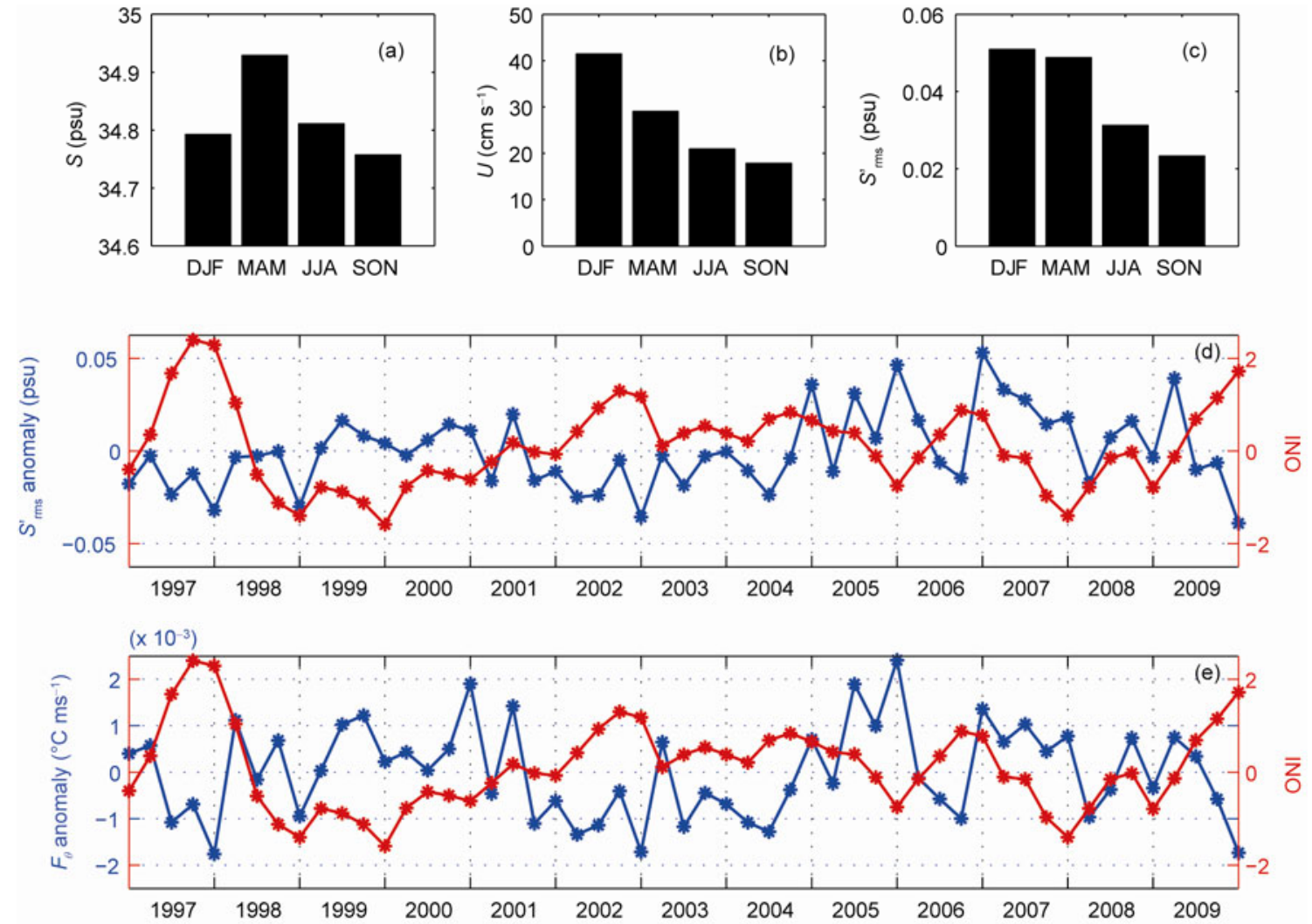

Figure 5 (a)-(c) Annual cycles of salinity $S$, zonal geostrophic velocity $U$, and rms salinity anomaly $S_{\text {rms }}^{\prime}$ at $5^{\circ} \mathrm{N}$ between $22.5-25.5 \sigma_{\theta}$. (d) Comparison between $S_{\text {rms }}^{\prime}$ anomaly (blue) and the ONI (red). (e) Comparison between cross-front potential temperature flux $F_{\Theta}$ anomaly (blue) and the ONI (red). Both $S_{\text {rms }}^{\prime}$ and $F_{\Theta}$ anomalies are between $24.5-25.0 \sigma_{\theta}$ at $5^{\circ} \mathrm{N}$ with the annual cycle subtracted. 
where $v_{L}$ is the meridional velocity caused by interleaving, $\overline{S_{y}}$ is the background lateral salinity gradient, $K_{V}$ is the vertical eddy diffusivity for salinity, and $S_{z z}$ is the vertical curvature of salinity. For a crude estimation, the cross-front potential temperature flux $F_{\Theta}$ is written as [7]

$$
F_{\Theta} \simeq \frac{\beta}{\alpha} v_{L} \Delta S=\frac{\beta}{\alpha} K_{V} S_{z z} \Delta S\left(\overline{S_{y}}\right)^{-1},
$$

where $\alpha$ and $\beta$ are thermal and saline expansion coefficients, respectively. Using the value of $K_{V}=1 \times 10^{-5} \mathrm{~m}^{2} \mathrm{~s}^{-1}$ and setting $\Delta S=2 S_{\text {rms }}^{\prime}$ between 22.5-25.5 $\sigma_{\theta}$, mean $F_{\Theta}$ can be coarsely estimated. Controlled by intrusion strength changes, $F_{\Theta}$ fluctuates with a peak-to-peak difference of $4 \times 10^{-3}{ }^{\circ} \mathrm{C} \mathrm{m}$ $\mathrm{s}^{-1}$ (Figure 5(e)) and shows even higher negative correlation with the ONI ( $r=-0.45$, significant at $99 \%$ confidence level). We can also estimate the effective lateral diffusion coefficient due to intrusions by $K_{L}=F_{\Theta} / \overline{\Theta_{y}}$, which shows a large variation from $O\left(10^{2} \mathrm{~m}^{2} \mathrm{~s}^{-1}\right)$ to $O\left(10^{3} \mathrm{~m}^{2} \mathrm{~s}^{-1}\right.$ ) (not shown).

\section{Summary and discussion}

Using the repeated high-quality CTD measurements of the JMA, we delineate spatial distribution of thermohaline intrusions along the $137^{\circ} \mathrm{E}$ section in the northwestern tropical Pacific. Intrusions are strikingly intensive in the vicinity of the NECC at the southern end of the section, with strength decreasing with depth and latitude. Intrusions in the Kuroshio, with similar hydrographic environment as in the NECC, are much weaker, confirming the hypothesis of previous studies $[7,11]$ that inertial instability at low latitudes plays an important role in driving strong intrusions.

For the first time in oceanographic literature, temporal variability of intrusions is addressed in this study. Pronounced variations of intrusion strength are found between $4^{\circ}-6^{\circ} \mathrm{N}$ : an evident seasonal cycle with a peak in winter; and interannual modulations related with ENSO, which tend to be weak (strong) during strong El Niño (La Niña) episodes. These variations are shown to be associated with the meridional displacement of the NECC and the North/South Pacific water boundary. The variations of intrusion strength also result in large fluctuations of cross-front potential temperature flux $F_{\Theta}$ and lateral diffusion coefficient $K_{\mathrm{L}} . F_{\Theta}$ shows a prominent negative correlation with the ONI, enhanced (reduced) during cold (warm) events.

Limited by the horizontal resolution and temporal length of the dataset, our estimation is crude. However, we believe that the revealed variations in intrusion strength, heat flux, and lateral diffusion are basically robust. These results suggest the potential importance of thermohaline intrusions in the tropical Pacific ocean/climate variability. As the direct thermocline water exchange between the western Pacific warm pool and subtropical North Pacific are greatly suppressed by a high potential vorticity barrier near $10^{\circ} \mathrm{N}$, lateral mixing at the NECC is especially important in the subtropical-tropical interaction. The intrusion-relevant poleward fluxes at the NECC are closely associated with the heat/salt budget of the warm pool, and thus may be involved in the recharge-discharge regime of ENSO [16]. Therefore, the role of intrusions in tropical ocean/climate processes cannot be ignored in the mixing parameterization scheme of numerical models.

This work was supported by the National Basic Research Program of China (2012CB417401) and the National Natural Science Foundation of China (40890152). The authors are grateful to the anonymous reviewers for their insightful comments.

1 Shcherbina A Y, Gregg M C, Alford M H, et al. Characterizing thermohaline intrusions in the North Pacific subtropical frontal zone. J Phys Oceanogr, 2009, 39: 2735-2756

2 Ruddick B R, Richards K J. Oceanic thermohaline intrusions: Observations. Prog Oceanogr, 2003, 56: 499-527

3 Bingham F M, Lukas R. The southward intrusion of North Pacific Intermediate Water along the Mindanao coast. J Phys Oceanogr, 1994, 24: 141-154

4 Qu T, Mitsudera H, Yamagata T. A climatology of the circulation and water masses distribution near the Philippine coast. J Phys Oceanogr, 1999, 39: 1488-1505

5 Xie L, Tian J, Hu D, et al. A quasi-synoptic interpretation of water mass distribution and circulation in the western North Pacific: I. Water mass distribution. Chin J Oceanol Limnol, 2009, 27: 630-639

6 Li Y, Wang F. Spreading and salinity change of North Pacific Tropical Water in the Philippine Sea. J Oceanogr, 2012, 68: 439-452

7 Richards K J, Banks H. Characteristics of interleaving in the western equatorial Pacific. J Geophys Res, 2002, 107: 3231

8 Lee J H, Richards K J. The three-dimensional structure of the interleaving layers in the western equatorial Pacific Ocean. Geophys Res Lett, 2006, 31: L07301

9 Richards K J, Edwards N R. Lateral mixing in the equatorial Pacific: The importance of inertial instability. Geophys Res Lett, 2003, 30: 1888

10 Beal L M. Is interleaving in the Agulhas Current driven by nearinertial velocity perturbation? J Phys Oceanogr, 2007, 37: 141-154

11 Edwards N, Richards K J. Linear double-diffusive-inertial instability at the equator. J Fluid Mech, 1999, 395: 295-319

12 Kashino Y, Ishida A, Hosoda S. Observed ocean variability in the Mindanao Dome region. J Phys Oceanogr, 2011, 41: 287-302

13 Qiu B, Joyce T M. Interannual variability in the mid- and lowlatitude western North Pacific. J Phys Oceanogr, 1992, 22: 10621079

14 Kashino Y, España N, Syamsudin F, et al. Observations of the North Equatorial Current, Mindanao Current, and Kuroshio Current system during the 2006/07 El Niño and 2007/08 La Niña. J Oceanogr, 2009, 65: $325-333$

15 Joyce T M. A note on the lateral mixing of water masses. J Phys Oceanogr, 1977, 7: 626-629

16 Jin F F. An equatorial ocean recharge paradigm for ENSO. Part I: Conceptual model. J Atmos Sci, 1997, 54: 811-829

Open Access This article is distributed under the terms of the Creative Commons Attribution License which permits any use, distribution, and reproduction in any medium, provided the original author(s) and source are credited. 